\title{
Findings of an evaluation of community and school-based reproductive health and HIV prevention programs in Kenya
}

\author{
Carolyne Njue ${ }^{1,}$, Helene A.C.M Voeten ${ }^{b}$, Eric Ohumac, C. \\ Looman $^{b}$, Dik F. Habbemab and lan Askew ${ }^{a}$ \\ a Population Council, PO Box 17643-00500 Nairobi, Kenya \\ ${ }^{b}$ Department of Public Health, Erasmus MC, University Medical Center, \\ PO Box 20403000 CA Rotterdam, The Netherlands \\ c University of Oxford, Nuffield Department of Medicine, Oxford, \\ United Kingdom
}

\begin{abstract}
Improving knowledge, attitudes, delaying onset of sexual activity and decreasing high-risk of sexual behaviour of young people are central components in strategic planning for $\mathrm{RH}$ programming. This paper presents findings of an evaluation of a public multi-sectoral adolescent reproductive health and HIV prevention program in rural Kenya. Study design was a community-randomized controlled trial. Crosssectional baseline and endline surveys were conducted to evaluate the impact of the interventions with regard to knowledge, attitude and practices. Results in intervention sites $A$ and $B$ as compared to the control site showed large impact on knowledge of sexual and reproductive health issues, a less significant impact regarding attitude, and a small but significant impact on sexual behaviour. The community-based intervention had a significant impact on knowledge and sexual behaviour. Adding a school-based intervention component didn't have a sustained improvement across board as anticipated. These findings underscore the need to strengthen capacities of public sector staff and enhance the robustness of strategy implementation.
\end{abstract}

Keywords: Premarital pregnancy, premarital sex, unmarried women, young motherhood, Adolescents, Sexual behaviour, Reproductive Health, HIV/AIDS, Intervention, Evaluation, Kenya

\footnotetext{
${ }^{1}$ Corresponding author

Population Council, Tel: +254 20 2713480; Email: cnjue@popcouncil.org

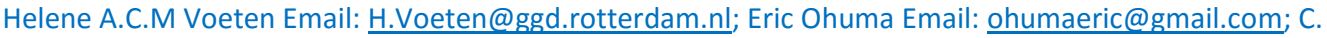
Looman Email: c.looman@erasmusmc.nl; Dik F. Habbema Email: j.d.f.habbema@erasmusmc.nl; lan Askew Email: iaskew@popcouncil.org
} 


\section{Résumé}

Améliorer la connaissance, les attitudes, retarder le début de l'activité sexuelle et réduire les pratiques sexuelles à haut risque des jeunes constituent les éléments centraux de la planification stratégique de la programmation de santé de la reproduction. Cet article présente les résultats de l'évaluation d'un programme multisectoriel en santé publique portant sur la santé de la reproduction et la prévention du VIH pour les adolescents en milieu rural au Kenya. L'étude est construite à partir d'un essai contrôlé randomisé au niveau des communautés. Des enquêtes transversales faisant l'état des lieux au démarrage et à la fin du projet ont été menées pour évaluer l'impact des interventions par rapport à la connaissance, à l'attitude et aux pratiques. Les résultats dans les sites d'intervention $A$ et $B$, comparés à l'échantillon de contrôle, ont montré un impact fort sur la connaissance relative à la sexualité et à la santé de la reproduction, un impact moins important par rapport aux attitudes et un impact faible mais significatif sur les pratiques sexuelles. Les interventions au niveau de la communauté ont un impact significatif sur la connaissance et le comportement sexuel. La dimension supplémentaire des interventions en milieu scolaire n'a pas eu l'impact durable escompté dans tous ces secteurs. Ces résultats soulignent la nécessité de renforcer les capacités des employés du secteur de la santé publique et de promouvoir la consolidation de la mise en œuvre de la stratégie.

Mots-clés : la grossesse avant le mariage, le sexe avant le mariage, les femmes célibataires, les jeunes mères, adolescents, comportement sexuel, santé de la reproduction, VIH/SIDA, intervention, évaluation, Kenya

\section{Introduction}

Teenage is an age of adventure, of exploring new things; it is an age when teenagers experience a range of mental and bodily changes. They are faced with different situations and pressures of growing up and have to deal with these challenges without feeling confused and overwhelmed. Several studies have shown that myriad and complex individual and contextual factors lead to high-risk of sexual behaviour for young people (UNICEF et al. 2002, Mugisha et al 2003, Amoateng et al. 20I4, Muindi et al. 20l4).

In Kenya, about one third of the population comprise of young people 10-
24 years, approximately three-quarters have had sex by the age of 20 , and with a median age at first sexual intercourse of 17.8 years (KDHS 2004). HIV prevalence amongst young people 15-24 years (3\% women; I. I\% men) is largely attributed to new infections (KAIS 20I2). The DHS survey of 2003/04 indicates that one in ten adolescents aged 15-19 years reported that they have experienced sexual violence, and one in five was coerced into their first sexual experience. Almost half of all females become pregnant before the age of 20 (KDHS 2004). The DHS survey also found out that comprehensive knowledge about HIV prevention among 
young people is below $50 \%$. These figures show that there is a need to educate the Kenyan youth on sexual behaviour, HIV/STI prevention of HIV/STIs and sexual coercion.

Efforts to provide comprehensive sexuality education and reproductive health services to sexually active adolescents were shrouded with controversy and opposition, because of the concern that provision of comprehensive sex and AIDS education would lead to promiscuity, although no studies had shown such a link (MOH I 997, KNASCOP et al. 2003). As a result of this belief and government holdbacks, there was a lack of systematic and comprehensive sex and AIDS educational programmes for in and out of school youth (MOH 1997, KNASCOP et al. 2003, Warren et al. 200I). Parents, teachers, health professionals and other related practitioners often lacked the capacity to educate adolescents about sexuality. Adolescents relied on friends, peers and the media for (often faulty) information on sexual and reproductive health care (Njue et al. 2009, Warren et al. 200I). With this in mind, the Population Council, with support from USAID introduced, jointly with the Kenyan government and PATH (the Program for Appropriate Technology in Health), the 'Kenya Adolescent Reproductive Health Project' in Kenya. The purpose of the current paper is to describe the evaluation of this multipronged approach and the effect of the interventions on adolescents' knowledge, attitudes and sexual behaviour.

\section{Methods}

\section{The interventions}

The Kenya Adolescent Reproductive health Project (KARHP) has developed and tested innovative approaches for public sector, multi-sector authorities to deliver sexual and reproductive health information and services to young people (both in and out of school), their parents, teachers and community leaders. The project aimed to initiate discussions of, and increase knowledge of sexual and reproductive health and HIV prevention among young people aged 10 to 19 years, encourage healthy and responsible attitude towards sexuality, delay first sex among younger adolescents, promote safer sex practices among the sexually active adolescents, and decrease high-risk of sexual behaviour (defined as sex without using a condom/contraceptive or non-consensual sex). This was done through strengthening public sector, social, educational and health services in rural Kenya. Through collaborative partnership with three government ministries, a complementary package of interventions was designed and implemented through schools and in the community, including linking young people with health facilities.

The Ministry of Gender, Sports, Culture and Social Services took the lead in implementing the community-based intervention arm. Local civic and religious leaders and parents were engaged through strategies of participatory community mobilization, community-wide discussions. Four Social Development Assistants (one in each site) were trained to support work with 20 civic and 80 religious leaders and with 83 peer group leaders and I 20 out-ofschool peer educators. The Social 
Development Assistants supervised the peer educators and organised community meetings, barazas (formal meeting called for by the local civic leaders), local folklore such as drama/theatre and video show, targeting public and religious events to reach young people and also to sensitise community members on adolescent reproductive and sexual health issues. A training manual was used to mentor and coach the peer educators and peer group leaders (Martin 2007). The outreach activities, including community dialogue sessions were monitored and delivered through the local community development offices.

The school-based intervention arm led by the Ministry of Education, Science and Technology, consisted of a teacher-led, peer-assisted in-school programme. A 34part life-planning skills curriculum was developed with the ministry and curriculum sessions taught in class at least once a week over the three school terms. The curriculum content covered a range of topics including facts about HIV/AIDS, modes of transmission, sexuality, gender and STIs, pregnancy, and life skills focusing on risk behaviour (Behague et al. 2006). Schools also integrated the life-skills sessions into extracurricular activities conducted after class hours through activities such as theatre, debates, festivals and essay competitions. Moreover, the schools linked the students to health centres whenever required. In total, six divisional level staff members, 29 head teachers and 74 Guidance and Counselling teachers from all 6 secondary schools and 21 of 25 primary schools in the intervention site $B$ were trained (the 4 smallest schools were not included) to offer these sessions. The teachers were supported by 600 peer educators drawn from among the pupils.

Both intervention arms were supported by the Ministry of Health. Sixteen health centres (out of the 19 situated in the study sites) were supported to improve services for young people at their facilities. They were facilitated to recruit and support peer educators, as well as create designated spaces explicitly for group and individual meetings, and counselling. In total, 38 providers ( 33 nurses, 4 clinical officers, and I medical doctor) from the 16 facilities were given a systematic orientation in effective service delivery for young people $(\mathrm{MOH}$ 1997). However, participating clinics found it difficult to spare rooms to provide 'youth friendly' services, and records about the services they provided were poorly kept. Over time, the level of participation of the providers dwindled, at the end of the project none of them could be described as actively participating.

The project was done in three phases over 42 months. The intervention activities were implemented and sustained over 18 consecutive months (from March 2000 till August 2002), during which inputs, activities and project outputs were systematically monitored. The total population of the intervention sites was around 85,000 , of which about half were adolescents aged 10-19 years old (CBS 200I).

\section{Site selection}

Two of the eight districts in Western Province of Kenya were selected - Vihiga and Busia - on the basis of high incidence of teenage pregnancies, high school dropouts, HIV and sexually transmitted 
infections (Warren et al. 200I). A multistage sampling procedure was applied. One division per district was randomly selected and included in the study - Sabatia Division in Vihiga and Butula Division in Busia. Within each division, a sub-sample of locations (an administrative unit) were identified if they met the eligibility criteria of: a population size of at least 15,000; at least one public health facility and any number of private health facilities; and a minimum of ten primary and secondary schools. Taking into account the criteria base, six locations were selected for inclusion into the project, three each per district.

Subsequently, the selected locations (one in each district) were randomly assigned to one of the three intervention arms: the experimental site $A$ or $B$ or control site $C$. The two locations of site $A$ received the community-based intervention; the two site B locations received the community plus school-based intervention; whereas locations of site $\mathrm{C}$ were included as control sites to provide a comparison over time; no activities were implemented in these sites, but measures of the key dependent variables were made (Fig. I).

\section{Evaluation design}

To determine the impact of the multisector interventions, pre- and postintervention population-based surveys were conducted by the Population Council in 1999 and 2002, respectively, in the experimental site $A, B$ and control site $C$ and comparisons made between the findings in the interventions sites, and also with the control site. To study the effect of the interventions on the community as a whole, random samples were drawn for both the baseline and endline surveys, without individuals being followed-up. In each location, five enumeration areas (each EA has about 100-120 households) were included in the sample from an average total of 21 enumeration areas per location. For each sampled enumeration area, systematic sampling was done, with every fifth household with male and/or female adolescent(s) aged 10-14 years and I5-19 being considered eligible. Within a household only one adolescent per sex and age group was interviewed, through random selection if necessary.

A baseline and endline semi-structured questionnaire was developed to collect data with respect to demographic characteristics of adolescents and a range of the outcome variables that were to be addressed by the program. Specific areas where the questions were directed during the survey include adolescents' understanding of reproductive physiology, knowledge about and attitudes towards reproductive health and sexual health and health-seeking behaviour such as the prevention of STIs including HIV/AIDS. The questionnaire was translated from English to Kiswahili and then back translated to English and pre-tested to ensure construct and face validity. Adolescents could respond to the questionnaire in English or Swahili. The endline questionnaire used after 18 months of implementation had additional questions on the exposure and participation in an intervention.

Confidentiality was assured by explaining to the adolescents that only the researchers had access to their questionnaires, that no names were 
attached to the questionnaires, and that their responses would not be discussed with school or project staff. Clearance and ethical approval for the research were obtained from the Kenyan national review board and from the Population Council's Institutional Review Board. Before each survey round, informed consent was received from all adolescents, and written assent from parents or guardians for those aged less than 18 years. Semi-structured interviews were conducted individually with respondents and in privacy, by trained same-sex interviewers.

The ultimate goal of these interventions was to encourage or facilitate efforts to delay onset of sexual activity or decrease high-risk of sexual behaviour of young people. From a total of about 45,000 adolescents in sites $A$ and $B$, about $I$ in 20 was interviewed in each survey round (i.e. 2400). Sample sizes were calculated to be able to detect a $40 \%$ reduction in the proportion of those who have ever had sexual intercourse among the 10-14 age group, and a $40 \%$ increase in the proportion of those sexually active using modern contraceptives (including condoms) in the I5-19 age group. Since the estimated rates of sexual experience were much lower among girls than among boys, and among the younger age groups than old age groups, the study required a larger sample size for girls and the younger age groups, to be able to detect the aimed effect size.

\section{Data analysis}

Following data cleaning, SPSS Version 15 was used for statistical analysis. Weighted data were used to compensate for the oversampling of women and the younger age group. The analyst adjusted outcomes to account for possible differences between baseline and endline regarding age, sex, and location. Statistical analyses compared baseline and endline for the sites $A, B$ and $C$, using logistic regression analyses with the various binary knowledge/attitude/behaviour variables as outcomes, and the variable "survey" (baseline or endline) as predictor. For the continuous variable "number of lifetime partners" the analyst used loglinear regression analysis. Age of first sex was analysed by survival analysis, using Kaplan Meier to calculate the mean age at fist sex, and Cox regression to calculate $\mathrm{p}$-values.

The team expressed the impact of the interventions by giving the percent points improvement in the intervention sites measures, compared to control sites (pre/post difference in the intervention sites minus pre/post difference in control site). To estimate $p$-values of the impact of the interventions, the analyst performed logistic regression analyses with the various binary knowledge/attitude/behaviour variables as outcomes, and the variables "site" (A, B, or C), "survey" (baseline or endline), and the interaction of these two as predictors; the $\mathrm{p}$-values of the interaction terms (site $A$ versus $C$ and site $B$ versus $C$ ) were the outcomes of interest. Using the same predictors, team performed Cox regression analysis for "age at first sex" and loglinear regression analysis for the variable "number of lifetime partners", to estimate the impact of the interventions.

The total baseline and endline survey sample sizes were 3,522 and 3,758, respectively. For the data presented, 
response rates varied, ranging from $78 \%$ to $99 \%$, with older girls having the lowest response rates.

\section{Results}

Evidence from project management information system indicates that the interventions succeeded in implementing a large number of activities in schools and with community organizations (see Table I). In the community-based intervention, over 500 community activities were organized and over 15,000 meetings with individuals were realized in site $A$ and $B$ together. In the school-based intervention (site B only), an average of 14 sessions (of the 34 Life-skills curriculum sessions) were taught per teacher, and over 60 school activities were organized per school.

Results from the project evaluation showed that there were little sociodemographic differences between sites, and between baseline and endline surveys (see Table 2). Of those interviewed, the vast majority had attended school; over 80 percent were in school; over half lived with both parents and one quarter lived with their mother only. Between I-3\% of interviewed adolescents were married.

Baseline versus endline knowledge is described in Table 3. Multivariate analyses show that in both intervention sites, there is a significant and positive effect on knowledge/awareness of sexual and reproductive body functions, contraception, STI, and abstinence as a way to avoid STD/HIV. In the intervention site $A$, there is also a significant positive impact on knowledge of faithfulness as a way to avoid STD/HIV, and asking a partner to be faithful. Interventions in site $B$ had no impact on knowledge of HIV/AIDS (although knowledge remained very high at $96 \%$ ), and on knowledge of condom use as a way to avoid STD/HIV (which increased more in site $A$ and $C$ than in site B). 
Table I: Overview of activities implemented in the community- and school-based interventions

\begin{tabular}{|c|c|}
\hline \multicolumn{2}{|l|}{ Community-based activities' } \\
\hline Persons & Activities \\
\hline \multirow[t]{7}{*}{83 Peer group leaders } & 16I Group discussions \\
\hline & 92 Drama presentations \\
\hline & 55 Outreach meetings \\
\hline & 90 Condom demonstrations \\
\hline & 35 Video shows \\
\hline & I8 IEC material distributions \\
\hline & 34 Sport tournaments and other events \\
\hline 4 Social Development Assistants +80 Religious leaders & $\begin{array}{l}60 \text { Community meetings, covering over } 7000 \\
\text { persons }\end{array}$ \\
\hline \multirow[t]{4}{*}{120 Peer educators +83 Peer group leaders } & $\begin{array}{l}\text { I5,669 Individual meetings, covering the following } \\
\text { topics }\end{array}$ \\
\hline & $\begin{array}{lcc}- & \text { STI } & (23 \%) \\
- & \text { relationships } & (13 \%)\end{array}$ \\
\hline & $\begin{array}{lcc}- & \text { drug } & \text { use } \\
- & \text { teenage } & \text { pregnancy } \\
- \text { - contraceptives (9\%) } & \end{array}$ \\
\hline & - other (34\%) \\
\hline \multicolumn{2}{|l|}{ School-based activities } \\
\hline Persons & Activities \\
\hline \multirow[t]{2}{*}{74 Guidance and Counselling Teachers in 27 Schools } & I4 Curriculum sessions (average per teacher) \\
\hline & $\begin{array}{l}2 \text { Group discussions per month (average per } \\
\text { teacher) }\end{array}$ \\
\hline \multirow[t]{5}{*}{600 Peer educators } & 26 Group discussions (average per school) \\
\hline & I6 Drama presentations (average per school) \\
\hline & I4 Outreach meetings (average per school) \\
\hline & 4 Video shows (average per school) \\
\hline & 2 Condom demonstrations (average per school) \\
\hline
\end{tabular}

'Total number of community-based activities in sites A and B together 
African Population Studies Vol. 29, No. 2, Supplement, 2015

Table 2: Comparison of socio-demographic characteristics of respondents aged 10-19 at baseline $(n=3522)$ and endline $(n=3758)$

\begin{tabular}{|c|c|c|c|c|c|c|c|c|c|}
\hline & \multicolumn{2}{|c|}{$\begin{array}{l}\text { Community } \\
\text { site A }\end{array}$} & \multirow{2}{*}{$\frac{\text { intervention }}{\mathrm{p}^{- \text {value }^{2}}}$} & \multicolumn{3}{|c|}{$\begin{array}{l}\text { Community + school-intervention } \\
\text { site B }\end{array}$} & \multicolumn{3}{|l|}{$\begin{array}{l}\text { Control } \\
\text { site C }\end{array}$} \\
\hline & $\begin{array}{l}\text { Baseline, } \\
\% \\
(n=\mid 186)\end{array}$ & $\begin{array}{l}\text { Endline, } \\
\% \\
(n=1232)\end{array}$ & & $\begin{array}{l}\text { Baseline, } \\
\% \\
(n=1222)\end{array}$ & $\begin{array}{l}\text { Endline, } \\
\% \\
(n=1279)\end{array}$ & p-value ${ }^{2}$ & $\begin{array}{l}\text { Baseline, } \\
\% \\
(\mathrm{n}=|| \mid 4) \\
\end{array}$ & $\begin{array}{l}\text { Endline, } \\
\% \\
(n=1247)\end{array}$ & $\mathrm{p}$-value ${ }^{2}$ \\
\hline Sex & & & 0.9 & & & 0.9 & & & 0.9 \\
\hline Male & 49 & 49 & & 50 & 50 & & 48 & 48 & \\
\hline Female & 51 & 51 & & 50 & 50 & & 52 & 52 & \\
\hline Age, mean (yrs) & 14.0 & 14.0 & 1.0 & 14.1 & 14.1 & 1.0 & 14.2 & 14.2 & 1.0 \\
\hline Ever attended school & 96 & 96 & 0.4 & 97 & 96 & 0.9 & 98 & 97 & 0.2 \\
\hline Currently attending school & 81 & 84 & 0.02 & 85 & 89 & 0.02 & 84 & 83 & 0.7 \\
\hline Marital status & & & 0.2 & & & 0.3 & & & 0.2 \\
\hline Single/Never married & 97 & 98 & & 98 & 98 & & 99 & 98 & \\
\hline Married & 3 & 2 & & 2 & 2 & & 1 & 2 & \\
\hline Living with: & & & 0.001 & & & 0.7 & & & 0.2 \\
\hline Both parents & 60 & 57 & & 51 & 50 & & 53 & 50 & \\
\hline Mother only & 24 & 21 & & 28 & 30 & & 29 & 31 & \\
\hline Father only & 3 & 5 & & 6 & 5 & & 4 & 3 & \\
\hline Other arrangements & 13 & 17 & & 15 & 16 & & 15 & 16 & \\
\hline
\end{tabular}

'Data are controlled for differences between baseline and endline regarding age, sex and location.

${ }^{2}$ p-values are calculated using the Chi-squared test for categorical variables and the Student's T-test for "age”.

http://aps.journals.ac.za

1942 
Table 3: Knowledge, attitude and sexual behaviour of respondents aged I0-19 at baseline $(n=3522)$ versus endline $(n=3758)^{\prime}$

\begin{tabular}{|c|c|c|c|c|c|c|}
\hline & $\begin{array}{l}\text { Community intervention } \\
\text { site A }\end{array}$ & $\begin{array}{l}\text { Community }+ \\
\text { intervention site } B\end{array}$ & school & $\begin{array}{l}\text { Control } \\
\text { site C }\end{array}$ & & $\begin{array}{l}\text { Impact of the } \\
\text { interventions }{ }^{2}\end{array}$ \\
\hline Selected outcomes & $\begin{array}{ll}\text { Baseline, } & \text { Endline, } \quad p-\text {-value }^{3} \\
\% & \% \\
(n=1186)(n=1232)\end{array}$ & $\begin{array}{l}\text { Baseline,\% Endline, } \\
\begin{array}{ll}(n=1222) & \% \\
& (n=1279)\end{array}\end{array}$ & p-value ${ }^{3}$ & $\begin{array}{l}\text { Baseline, } \\
\% \\
(n=|| \mid 4)\end{array}$ & $\begin{array}{l}\text { Endline, } \quad \mathrm{p}-\text {-value }^{3} \\
\% \\
(\mathrm{n}=1247)\end{array}$ & $\begin{array}{l}\text { A vs. B vs. } \\
\text { C, } \%^{3} \text { C, } \%^{3}\end{array}$ \\
\hline
\end{tabular}

Knowledge of sexual and reproductive health

Ever heard of at least 3 of 6 sexual and reproductive 61 body functions ${ }^{4}$

Ever heard of contraception

Ever heard of HIV/AIDS

Ever heard of sexually transmitted infections (STI)

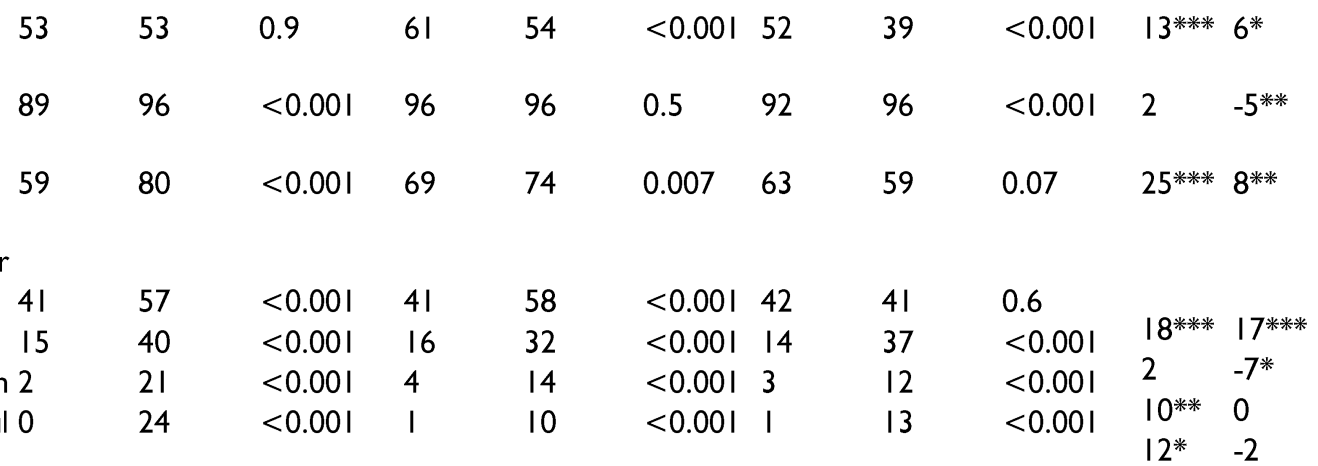

69

$<0.001$

67

76

$<0.00164$

59

0.01

$13 * * * 14 * * * *$

Mentioned the following ways to avoid getting STI or HIV/AIDS:

Abstain

Use

$\mathrm{Be}$

Ask partner to be faithful

\begin{tabular}{|c|c|c|c|c|c|c|c|c|c|c|}
\hline 53 & 53 & 0.9 & 61 & 54 & $<0.001$ & 52 & 39 & $<0.001$ & $13^{* * * *}$ & 6* \\
\hline 89 & 96 & $<0.001$ & 96 & 96 & 0.5 & 92 & 96 & $<0.001$ & 2 & $-5 * *$ \\
\hline (STI) & 80 & $<0.001$ & 69 & 74 & 0.007 & 63 & 59 & 0.07 & 25 **** & $8 * *$ \\
\hline $\mathrm{Or}$ & & & & & & & & & & \\
\hline 41 & 57 & $<0.001$ & 41 & 58 & $<0.001$ & 42 & 41 & 0.6 & & \\
\hline 15 & 40 & $<0.001$ & 16 & 32 & $<0.001$ & 14 & 37 & $<0.001$ & $18 * * *$ & $17^{* * * *}$ \\
\hline condom 2 & 21 & $<0.001$ & 4 & 14 & $<0.001$ & 3 & 12 & $<0.001$ & 2 & $-7^{*}$ \\
\hline faithful 0 & 24 & $<0.001$ & I & 10 & $<0.001$ & I & 13 & $<0.001$ & $\begin{array}{l}10 * * \\
12 *\end{array}$ & $\begin{array}{l}0 \\
-2\end{array}$ \\
\hline
\end{tabular}

\section{Reported attitude towards sexuality and reproductive health}

Disapproved of men having pre-marital sex $(n=4 \mid I 0) 83$
0.001

91

85

$0.4 \quad 1 \mathrm{I} * * * 2$
1943

91

91

$0.8 \quad 87$

87


African Population Studies Vol. 29, No. 2, Supplement, 2015

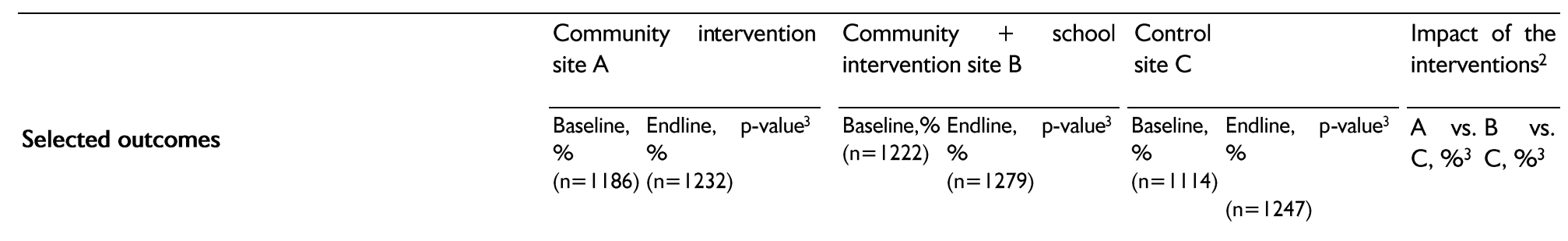

\begin{tabular}{lllllllllllll}
\hline Disapproved of women having pre-marital $\operatorname{sex} 86$ & 92 & 0.01 & 92 & 91 & 0.9 & 87 & 86 & 0.8 & $7^{* * *}$ & I
\end{tabular}
$(n=4088)$

Approved use of condoms by sexually active $73 \quad \begin{array}{llllllllllll}82 & 0.003 & 63 & 74 & <0.00 \mathrm{I} & 58 & 68 & 0.009 & -\mathrm{I} & \text { I }\end{array}$ adolescents $(n=4246)$

Approved use of contraceptives by sexually active $\begin{array}{llllllllll}64 & 67 & 0.4 & 52 & 56 & 0.3 & 42 & 40 & 0.6 & 6\end{array}$
adolescents $(n=4 \mid 26)$

\section{Reported sexual behaviour}

Ever had

Boys

Girls

Age-group 10-14

Mean age at first sex

Boys

Girls

For those who ever had sex:

Had sex in the past 6 months

http://aps.journals.ac.za

sex

$\begin{array}{lllllllllll}38 & 29 & 0.002 & 27 & 23 & 0.11 & 34 & 36 & 0.5 & -1 \text { I** } & -6 \\ 21 & 21 & 0.9 & 17 & 15 & 0.4 & 15 & 19 & 0.04 & -5 & -6 * \\ 15 & 9 & <0.001 & 7 & 7 & 0.8 & 9 & 13 & 0.02 & - & -4 \\ & & & & & & & & & \end{array}$

$\begin{array}{lllllllllll}15.7 & 17.4 & 0.046 & 16.5 & 16.8 & 0.3 & 16.2 & 15.9 & 0.3 & 2.0 * & 0.6 \\ 17.3 & 17.1 & 0.2 & 17.5 & 17.6 & 0.4 & 17.6 & 17.1 & 0.003 & 0.3 & 0.6 * *\end{array}$

$(n=227)(n=358) \quad(n=263)(n=250) \quad(n=210)(n=428)$

$\begin{array}{lllllllllll}42 & 42 & 0.8 & 44 & 42 & 0.6 & 38 & 46 & 0.07 & -8 & -10\end{array}$


African Population Studies Vol. 29, No. 2, Supplement, 2015

\begin{tabular}{|c|c|c|c|c|c|c|c|c|c|c|c|}
\hline \multirow[b]{2}{*}{ Selected outcomes } & \multicolumn{3}{|c|}{$\begin{array}{l}\text { Community } \\
\text { site } A\end{array}$} & \multicolumn{2}{|c|}{$\begin{array}{l}\text { Community }+ \\
\text { intervention site } B\end{array}$} & school & \multicolumn{3}{|l|}{$\begin{array}{l}\text { Control } \\
\text { site C }\end{array}$} & \multicolumn{2}{|c|}{$\begin{array}{l}\text { Impact of the } \\
\text { interventions }{ }^{2}\end{array}$} \\
\hline & $\begin{array}{l}\text { Baseline, } \\
\% \\
(n=\mid 186)\end{array}$ & $\begin{array}{l}\text { Endline, } \\
\% \\
(n=1232)\end{array}$ & p-value 3 & $\begin{array}{l}\text { Baseline,\% } \\
(n=1222)\end{array}$ & $\begin{array}{l}\text { Endline, } \\
\% \\
(n=1279)\end{array}$ & p-value & $\begin{array}{l}\text { Baseline, } \\
\% \\
(n=|| \mid 4)\end{array}$ & $\begin{array}{l}\text { Endline, } \\
\% \\
(n=1247\end{array}$ & p-value ${ }^{3}$ & $\begin{array}{l}\text { A vs. } \\
\text { C, \% }{ }^{3}\end{array}$ & $\begin{array}{l}\text { B vs. } \\
\text { C, \% }\end{array}$ \\
\hline Mean number of lifetime partners ${ }^{6}$ & 2.3 & 2.6 & 0.002 & 2.8 & 2.7 & 0.3 & 2.4 & 2.5 & 1.0 & $0.2 *$ & -0.2 \\
\hline Currently uses modern contraceptive & 25 & 30 & 0.2 & 38 & 31 & 0.1 & 33 & 30 & 0.5 & 7 & -4 \\
\hline Age-group I5-19 & 32 & 34 & 0.7 & 41 & 37 & 0.4 & 38 & 38 & 0.9 & 2 & -4 \\
\hline Used condom at last sex & 25 & 30 & 0.2 & 35 & 32 & 0.5 & 27 & 30 & 0.3 & 1 & -7 \\
\hline Used modern contraceptive or condom at first sex & 14 & 20 & 0.07 & 23 & 19 & 0.3 & 20 & 16 & 0.2 & $10 *$ & 0 \\
\hline Ever had non-consensual sex ${ }^{7}$ & 16 & 12 & 0.2 & 22 & 13 & 0.008 & 14 & 19 & 0.08 & $-9 *$ & $-15^{* * *}$ \\
\hline
\end{tabular}

vs. $=$ versus, ${ }^{*} \mathrm{p}<0.05,{ }^{* *} \mathrm{p}<0.01,{ }^{* * *} \mathrm{p}<0.001$

I Data are controlled for differences between baseline and endline regarding age, sex and location.

2 Percent points improvement in intervention group, compared to control group (pre-post difference in intervention group minus pre-post difference in control group).

${ }^{3} \mathrm{p}$-values are obtained through logistic regression for binary outcomes, Cox regression for "Mean age at first sex", and loglinear regression for "Mean number of lifetime partners". To estimate the p-value of the impact of the interventions, "site" (A, B, or C), "survey" (baseline or endline), and the interaction of these two were taken as predictors; the $p$-values of the interaction terms (site $A$ versus $C$ and site $B$ versus $C$ ) were the outcomes of interest.

${ }^{4}$ How the human body works, menstruation, ejaculation, dating, sexual intercourse and how girls get pregnant.

${ }^{5}$ Analysed through survival analysis, using Kaplan Meier to calculate the mean age at first sex, and using Cox regression to calculate p-values.

${ }^{6}$ Analysed through loglinear regression analysis.

7 Persuaded and/or forced. 
African Population Studies Vol. 29, No. 2, Supplement, 2015

Figure I: Maps showing the locations of Kenya, Western province, Vihiga and Busia districts and study sites

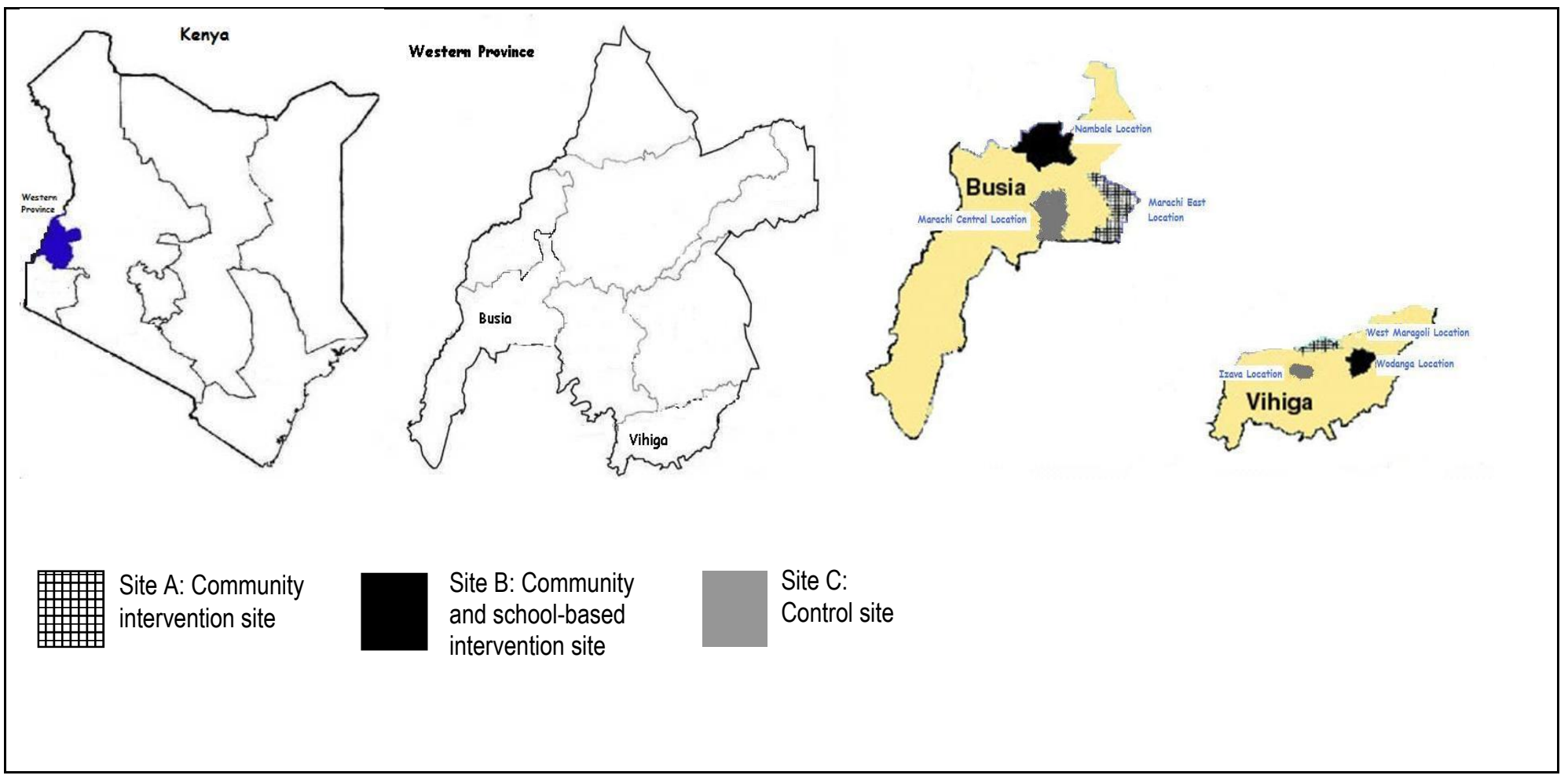


Regarding attitude, disapproval of premarital sex for men and women increased in intervention site $A$, but remained equal in site $B$ and site $C$ (Table 3). Approval of condom use increased in all sites whereas approval of contraceptives remained equal in all sites.

The proportion of sexually experienced male adolescents aged $10-19$ years decreased in intervention site $\mathrm{A}$ (from $38 \%$ to $29 \%, p=0.002$ ), whereas in the control site $\mathrm{C}$, it increased for girls in the same age (from 15\% to 19\%, p=0.04) (Table 3). The interventions had a significant positive impact for boys in intervention site $A$ and for girls in intervention site B. For adolescents aged 10-14, the interventions expected to decrease the proportion ever having had sex by $40 \%$. In site A, this proportion declined $44 \%$ (from $15 \%$ to $9 \%)$. In site B it increased slightly by $3 \%$, whereas in the control site it increased $44 \%$ (from $9 \%$ to $13 \%$ ); thus, compared to the control sites, site $B$ had a decrease of about $40 \%$ (although the impact was not-significant, $p=0.1$ ). Mean age of first sex increased significantly for boys in the intervention site A, going from 15.7 to 17.4 years. For the girls living in intervention site $A$ and for boys and girls in intervention site $B$ it remained equal. In the control site $C$ however, the age of first sex decreased for girls, from 17.6 years to 17.I years; while for boys it remained equal. Suggesting that interventions had positive effects on the age of first sexual encounter, for boys in intervention site $A$ and for girls living in site B.

Although the interventions paid a lot of attention to enhancing behaviour change among the sexually active adolescents, overall the interventions had no significant impact on sexual activity in the past 6 months, on contraceptives or condom use during the last sexual encounter (Table 3). Intervention activities in site $A$ had a positive effect on contraceptive/condom use during first sex, whereas both interventions had a positive effect on nonconsensual sex (almost halving it in site $B$, whereas it increased in the control site). Results also show that the number of lifetime partners slightly increased in site $A$ versus the control site $(p=0.04)$.

During the endline survey, $20 \%$ and $35 \%$ of respondents in site $A$ and $B$ respectively, reported to have ever participated in any intervention activity. Only $3 \%$ of adolescents in site $C$ reported to have participated in any intervention activity, indicating negligible contamination. Participation in any intervention activity was defined as having attended/taken part in either the community or school-based intervention activities, or in both intervention arms during this period.

\section{Discussion}

This study evaluates the population-level effects of a community and a community plus school-based intervention approach in improving knowledge on sexual and reproductive health including HIV prevention, promoting healthy and responsible attitude towards sexuality, safer sex practices, delaying sexual activity and decreasing high-risk of sexual behaviour for young people in Western Kenya. The study results showed that young people living in the intervention sites had an increased awareness of sexual and reproductive body functions, 
contraceptives and STI. Knowledge of abstinence as a method to prevent HIV/STI also increased in both interventions, illustrating that abstinence as a preventive behaviour was well communicated. Interventions in site B seem to have no impact on awareness of HIV/AIDS, though it remained above $95 \%$. One should note that such extremely low or high percentages, i.e. below $5 \%$ or over $95 \%$, influence $\mathrm{p}$-values to be highly significant. Moreover, interventions in site $B$ also seem to have a negative impact on knowledge of condom as a way to avoid STI/HIV infection. This outcome could suggest that condoms remains a difficult subject to be discussed in schools, which may be related to the disapproval of programmes providing comprehensive sex and AIDS education (Njue et al. 2009).

The interventions had a less significant impact regarding attitude. The interventions did not challenge the attitude regarding premarital sex. Attitude remained conservative in all sites, and even reinforced less favourable attitudes towards premarital sex in the communitybased intervention. This confirms findings in literature that exposure to factual and accurate sexual and reproductive health information does not promote a 'promiscuous' attitude (Cochrane Collaborative Review Group 2004, Kirby et al. 2007). Approval of condom use for those who are sexually active increased in all sites. Midway through the implementation, a school-based HIV/AIDS curriculum was launched nation-wide and intense mass media campaigns used to promote messages. Sensitisation on condom use for pregnancy and disease prevention could contribute to the changes observed throughout the area including the control sites.

The interventions had a small but significant impact on sexual behaviour. The ultimate goal of the multi-sector interventions was to promote and encourage a delay in onset of sexual activity, and enable sexually active adolescents to practice less risky sex (risky sex being defined as unprotected sex i.e. sex without a condom/contraceptive or non-consensual sex). Indeed, the interventions succeeded in delaying sex: the proportion ever having had sex decreased significantly for boys living in intervention site $A$ and girls in intervention site $B$ (and non-significantly for girls living in intervention site $A$ and boys in intervention site B). For the ages 10-14 years, both interventions reached the goal of decreasing the proportion ever having had sex by $40 \%$ (compared to the control site). For sexually active adolescents, the interventions had a small positive impact: in site $A$ condom/contraceptive use at first sex increased, and in both intervention sites non-consensual sex decreased. The latter almost halved in site $B$, reflecting the emphasis on this topic during the school based activities (Njue et al. 2005). Conversely, the interventions did not have a statistically significant positive impact on condom use at last sex. The aim of enabling sexually active adolescents to practice less risky sex was thus only half reached.

Although the interventions had only a small positive impact for sexually active adolescents, this can be regarded as a success on the population level. Namely in the intervention sites, less adolescents did have sex, and the lower number of 
adolescents who did have sex, did not have more risky sex. Thus on a population level, risky sex decreased in both intervention sites. These results concur with the findings of recent reviews on the effectiveness of interventions on adolescent sexual and reproductive health and HIV/AIDS: none of the 83 evaluation studies reviewed found more frequent sexual activity among those already sexually active, nor a negative impact such as earlier sexual debut (Kirby et al. 2007).

Overall, the study design had several strengths. The interventions resulted from an intersectoral collaboration of the ministries of social services, education, and health, showing the feasibility to implement adolescent and youth sexual and reproductive health programs within the public sector and develop sustainable interventions (Kretzmann 1993, Kingsley et al. 1997, Population Council 2003,). Moreover, the interventions were implemented through existing structures, using teachers and the Social Development Assistants as key figures. Furthermore, only $3 \%$ of adolescents in the control sites had participated in some intervention activities, indicating negligible contamination.

The study had several limitations as well. Exposure to the interventions was rather low, with $20 \%$ and $35 \%$ of those surveyed in sites $A$ and $B$ respectively reporting to have ever participated in any intervention activity. Nonetheless, the study was able to show a substantial effect of the interventions. There may well have been some diffusion effect with the communities, or effect of other efforts as supported by the fact that, some measures in site C (control) also improved. For example, whilst the project was underway, HIV/AIDS education became mandatory in all schools, exposing young people in both the intervention sites and control sites to a wide array of HIV/AIDS activities. Mass media campaigns on HIV/AIDS were also common nationwide. However, the small changes observed in the control site suggest that these other activities had little effect. The study did rely on self-reported sexual behaviour, of which the validity is limited (Cleland et al. 2004). However, several techniques were used to ensure the highest possible validity: questions were derived from previously tested instruments, questionnaires were pilottested, and qualitative feedback from young people, used to further refine the instrument contents.

While one would have expected that site $B$ will have a sustained improvement across board, this was not the case. Results showed a larger impact in the sites with community based interventions (site A), though exposure to the interventions was lower in site A than site B $(20 \%$ versus $35 \%)$. Evidence from the project evaluation showed that implementation activities in intervention sites A were robust and intensely implemented providing a series of inter-linked activities and referrals. Over 500 community activities were organized and over 15,000 meetings with individuals were realized in sites A and B cumulatively. Outreach activities, individual and group encounters held by community development agents, religious leaders, and peer educators, not only exposed young people to reproductive health and HIV/AIDS messages and life skills but also improved 
parent-child communication creating an environment that is more promotive of preventive norms. Encouragingly, the school curriculum did contribute to school going adolescents' better understanding of sexual development, reproductive health, sexually transmitted diseases including HIV/AIDS and risk factors for STI/HIV.

The mixed findings on particular outcomes, either for different subgroups, or on different measures assessed is not unique and findings are similar to those recorded in other evaluations of adolescent reproductive health programs in developing countries (Fish et al. 2014). Similar to study findings, several studies have found that community-based HIV/AIDS programs can promote positive behaviour among young people and lead to lower HIV transmission (Erulkar et al. 2004, Jemmott \& Jemmott 1994, Agha 2002, Gallant \& Maticka-Tyndale 2004, Ross et al. 2007). A recent communitybased study found that secondary abstinence and the number of sex partners decreased among females, whereas among males in the project site, condom use increased (Erulkar et al. 2004). Results of a four-country study evaluating the impact of mass media, peer education and "youth friendly" services also found an increase in abstinence, contraceptive use rose and the numbers of partners decreased (Agha 2002). Conversely, several studies that evaluated programs on adolescent and HIV/AIDS risk reduction in African schools, showed a large impact on knowledge, a smaller impact on attitude and a modest impact on sexual behaviour (Kirby et al. 2007, Gallant and Maticka-Tyndale 2004, Shuey et al, 1999, Askew and Evelia 2007). These results indicate that knowledge and attitude are easy to change when schools engage adolescents, but behaviour is much more challenging (Gallant \& MatickaTyndale 2004).

Given the success of the some of the activities within the community and school based interventions, and expressions of interest by the members of the communities in Vihiga and Busia and the ministries, the Kenyan government decided to scale-up the successful components of the interventions, including an (improved) clinic-based component, into all other districts within Western Province. The scale-up was gradual and followed the pilot phase design (Askew \& Evelia 2007). The health services were placed within communities through the community-based health officers, with links to clinical staff. The cultural, social, religious and political factors have been taken into consideration to reflect the diverse local contexts during the scale-up. Based on the success of the replication efforts, the interventions have resulted into adolescent reproductive health and HIV prevention activities being introduced into public-sector personnel's routine work plans and budgets and being scaled up to other parts of Kenya (Askew \& Evelia 2007).

\section{Conclusion}

This study provides an invaluable opportunity and insights for policy makers and implementers engaging adolescents through community and school-based programs. The Kenya Adolescent Reproductive Health project has demonstrated that public sector, multisector interventions, can work to reach 
young people (both in and out of school) and their communities with sexual and reproductive health information and build essential life-skills. Overall, the project had a large impact on knowledge of sexual and reproductive health issues, a less significant impact regarding attitude, and a small but significant impact on sexual behaviour. These findings call for policy makers and program implementers to carefully design adolescents' reproductive health and HIV/AIDS interventions and continuously review their impact (Global HIV Prevention Working Group 2007, World Association for Sexual Health 2008) including focusing more explicitly on the content and materials used in the 'life skills' curriculum and how to link young people with referral services. The value of these programs could be more effective and sustained, if a more comprehensive approach to sex education could be reached at policy level, if an approach could be reached that encourages dialogue and openness about sex education, and if local public sector facilities could spare staff and space. The study findings also underscore the need to strengthen capacities of public sector staff and enhance the robustness of implementation, to improve the overall effectiveness of existing resources and initiatives.

\section{Contribution of Authors}

All authors contributed to the preparation of the article: C.N. contributed to the research process, data management, interpretation of data and writing the manuscript; H.V. contributed to the analysis, and writing and revising the manuscript; E.O. and C.L. contributed to the data analyses; D.H. contributed to the development of the idea and revision of the manuscript; and I.A contributed to the design of the community-randomized controlled trial, the research process, and revision of the manuscript.

\section{Acknowledgements}

This project was funded by the United States Agency for International Development (USAID) and the Netherlands organization for international cooperation (NUFFIC) in higher education, through a personal grant to the principal author.

The authors acknowledge and thank the Population Council for allowing use of the data. The authors extend great appreciation to all the stakeholders who collaborated in the implementation and evaluation of this pilot project. They thank the young people who participated in this study for openly sharing their private and intimate experiences; and the data collection team for their determination, dedication and professionalism that made it possible to collect these data.

\section{References}

Agha, S., (2002). A quasi-experimental study to assess the impact of four adolescent sexual health interventions in Sub-Saharan Africa, International Family Planning Perspectives, 28(2):6770 \& $113-118$

Askew lan and Evelia Humphres. 2007. Mainstreaming and scaling up the Kenya Adolescent Reproductive Health Project. Population Council. Frontiers in Reproductive Health Program 
Amoateng, A. Y., Kalule-Sabiti, I. \& Arkaah, Y. J. (20I4) The effect of sociodemographic factors on risky-sexual behaviours of adolescents in the North West Province of South Africa. African Population Studies 28(I), 487-498.

Behague, S., Christeson, K., Martin, S., Wysong, M., (2006). Tuko Pamoja [We are Together]: Adolescent Reproductive Health and Life Skills Curriculum. The Kenya Adolescent Reproductive Health Project, Program for Appropriate Technology in Health: Seattle WA.

Central Bureau of Statistics (Kenya), Ministry of Health (Kenya) and ORC Macro. Kenya Demographic and Health Survey (2003). Calverton, MD: CBS, ORC Macro, 2004.

Central Bureau of Statistics (200I). The 1999 Population and Housing Census. Ministry of Finance and Planning: Nairobi, Kenya

Cochrane Collaborative Review Group on HIV Infection and AIDS (2004). Evidence Assessment: Strategies for HIV/AIDS Prevention, Treatment and Care. University of California, San Francisco Institute for Global Health Cleland, J., et al., (2004). Monitoring sexual behaviour in general populations: a synthesis of lessons of the past decade, Sexually Transmitted Infections, 80(Suppl. II): iil-ii7

Erulkar, A. S., Ettyand, L. I. A., Onoka, C., et al. (2004). Behavior Change Evaluation of a Culturally Consistent Reproductive Health Program for Young Kenyans. International Family Planning Perspectives, 30(2):58-67.

Fish, H., Manlove, J., Moore, K. A., \& Mass, E., (20I4). What Works for Adolescent
Sexual and Reproductive Health: Lessons from Experimental Evaluations of Programs and Interventions. Child Trends. No. 2014-64.

Gallant, M., Maticka-Tyndale, E., (2004). School-based HIV prevention programmes for African youth. Soc Sci Med, 58:|337-|35|.

Global HIV Prevention Working Group (2007). Bringing HIV Prevention to Scale: An Urgent Global Priority. Bill and Melinda Gates Foundation and the Henry Kaiser Family Foundation.

Jemmott, J. B. III., \& Jemmott, L. S., ( 1994). Interventions for adolescents in community settings, in: DiClemente RJ and Peterson JL, eds., Preventing AIDS: Theories and Methods of Behavioral Interventions, New York: Plenum Press, pp. 14I-I74

Kenya National AIDS/STD/TB/Leprosy Control Programme, National AIDS Control Council, The MEASURE Project (2003). AIDS in Africa during the Nineties: Young People in Kenya. Carolina Population Center, University of North Carolina, Chapel Hill: USA.

Kingsley, G., McNeely, J., Gibson, J., (1997). Community building, Coming of Age. Washington, DC: The Urban Institute

Kirby, D. B., Laris B. A., \& Rolleri L. A., (2007). Sex and HIV education programs: their impact on sexual behavior of young people throughout the world, J Adolescent Health, 40(3): 206-217

Kretzmann, J. J., (1993). Building Communities from the Inside Out, a Path toward Finding and Mobilizing a Community's Assets. Chicago, IL: ACTA Publications 
Martin, S., (2007). Tuko Pamoja: A Guide for Peer Educators. The Kenya Adolescent Reproductive Health Project, Program for Appropriate Technology in health: Seattle WA.

Ministry of Health (1997). Reproductive Health / Family Planning Policy Guidelines and Standards for Service Providers. MOH, Division of Primary Health Care: Nairobi, Kenya.

Mugisha, F., Arinaitwe-Mugisha, J., \& Hagembe, B. O. N. (2003). Alcohol, substance and drug use among urban slum adolescents in Nairobi, Kenya. Cities, 20(4), 23I-240.

Muindi, K., Mudegeb, N., Beguya, D., \& Mberu, B. U. (20|4). Migration and sexual behaviour among youth in Nairobi's slum areas. African Population Studies, 28(3), I297-1309.

National AIDS and STI Control Programme (20I2). Kenya. Kenya AIDS Indicator Survey 2012: Final Report. Nairobi, NASCOP. June 2014.

Njue, C., Nzioka, C., Ahlberg, B. M., Pertet, A. M., \& Voeten H. A.C. M., (2009). "If you don't abstain, you will die of AIDS": AIDS education in Kenyan public schools. AIDS Educ.Prev. 2I(2): I56-I67

Njue, C., Askew I., \& Chege, J., (2005). "Non-consensual sexual experiences of young people in Kenya: boys as perpetrators an victims", in Jejeebhoy, S, I. Shah \& S. Thapa (editors) Sex
Without Consent: Young People in Developing Countries Zed Books, New York

Population Council (2003). "Kenya: Communities support adolescent reproductive health education, FRONTIERS OR Summary no. 33. Washington, DC: Population Council

Ross, D. A., Changalucha, J., Obasi, A. I. N., Todd, J., et al. (2007). Biological and Behavioral impact of an adolescent sexual health intervention in Tanzania: a community-randomized trial. AIDS, 21:1943-1955

Shuey, D. A., Babishangire, B. B., Omiat, S., Bangarukayo, H., (1999). Increased sexual abstinence among in-school adolescents as a result of school health education in Soroti district, Uganda. Health Educ Res 14:4I I-419.

UNICEF, UNAIDS and WHO (2002), Young People and HIV/AIDS Opportunity in Crisis. New York Warren, C., Chege, J., Askew, I., Radeny, S., \& Folsom, M., (200I). Improving the Reproductive Health of Adolescents in Kenya: A Report on the Baseline Study on Two Districts in Western Kenya, Population Council, Nairobi: Kenya.

World Association for Sexual Health. (2008). Sexual Health for the Millennium. A Declaration and Technical Document. Minneapolis, MN, USA: World Association for Sexual Health 